\title{
AGLOMERAÇÃO DE PROTEÍNA CONCENTRADA DO ARROZ EM PÓ EM LEITO FLUIDIZADO: INFLUÊNCIA DAS VARIÁVEIS OPERACIONAIS NO PROCESSO
}

\author{
L. S. KIS ${ }^{1}$, K. ANDREOLA ${ }^{1}$ e O. P. TARANTO ${ }^{1}$ \\ ${ }^{1}$ Universidade Estadual de Campinas, Faculdade de Engenharia Química \\ E-mail para contato: leticiakis@yahoo.com.br
}

\begin{abstract}
RESUMO - O objetivo desse trabalho foi realizar o estudo da aglomeração da proteína concentrada de arroz em pó em leito fluidizado e avaliar a influência da temperatura do ar e vazão de solução ligante na umidade final, fluidez, tempo de instantaneização e rendimento do processo. O processo de aglomeração resultou no aumento no diâmetro médio do material, o que melhorou o nível de fluidez e proporcionou melhores propriedades de instantaneização, viabilizando a sua utilização em diversas aplicações. A condição estudada que forneceu umidade final, fluidez e tempo de instantaneização desejáveis foi para temperatura do ar de $80{ }^{\circ} \mathrm{C}$ e vazão de solução ligante de $1,5 \mathrm{~mL} / \mathrm{min}$.
\end{abstract}

\section{INTRODUÇÃO}

As mudanças no estilo de vida e hábitos alimentares da população têm estimulado o aumento no consumo de alimentos industrializados de fácil preparo e consumo. Nesse sentido, torna-se evidente a necessidade de pesquisas para o desenvolvimento de alimentos que aliem qualidade nutricional, benefícios à saúde e praticidade no preparo e consumo.

As proteínas do grão de arroz destacam-se devido às suas propriedades nutritivas, nutracêuticas e funcionais, são ricas em aminoácidos essenciais e apresentam maior digestibilidade em comparação com a maioria das proteínas dos demais cereais (JULIANO, 1993). A proteína concentrada do arroz em pó apresenta partículas muito finas, o que dificulta sua solubilidade e dispersão em líquidos, comprometendo sua utilização. Sendo assim, o processo de aglomeração representa uma alternativa interessante para melhorar as propriedades de instantaneização desse material, viabilizando a sua utilização em diversas aplicações, tais como na formulação de produtos alimentícios e farmacêuticos.

O processo de aglomeração consiste na combinação de três fenômenos. A primeira etapa é a "umidificação e nucleação", que consiste no contato do agente ligante com o pó e na formação dos grânulos. A segunda etapa é a "consolidação e coalescência", na qual a colisão dos grânulos entre si provoca o aumento do tamanho das partículas. A última etapa é denominada de "atrito e quebra", na qual ocorre o rompimento dos grânulos devido ao impacto, desgaste ou compactação das partículas (IVESON et al., 2001). A aglomeração proporciona melhores propriedades de instantaneização, devido ao aumento do tamanho das partículas e da porosidade, o que permite a rápida penetração de líquido no interior do material, via capilaridade. Além disso, facilita as condições de transporte e armazenamento (HOGEKAMP e SCHUBERT, 2003). 
Leitos fluidizados são amplamente utilizados para a aglomeração de partículas em diversos setores industriais, pois apresentam elevadas taxas de transferência de calor e de massa, decorrentes da grande mistura do material sólido que é proporcionada pelo movimento das bolhas de gás (KUNII e LEVENSPIEL, 1991). A aglomeração em leitos fluidizados é realizada pela atomização de um líquido ligante sobre partículas em movimento agitado, de modo que o gás utilizado para fluidização das partículas também provoca a evaporação do ligante e a secagem do material.

No presente trabalho foi realizado o estudo do processo de aglomeração da proteína concentrada do arroz em pó em leito fluidizado, com o objetivo de avaliar a influência das variáveis operacionais, temperatura do ar e vazão de solução ligante na umidade final, fluidez, tempo de instantaneização e rendimento do processo.

\section{MATERIAIS E MÉTODOS}

\subsection{Matéria-Prima}

A matéria-prima utilizada nesse trabalho foi a proteína concentrada de arroz, fornecida pela empresa Grankow, localizada na cidade de Joinville, SC.

\subsection{Sistema Experimental}

O equipamento utilizado consiste de um leito fluidizado de acrílico Plexiglas ${ }^{\circledR}$. O ar é fornecido por um soprador de ar (WEG, 7,5 HP) e aquecido por uma resistência elétrica blindada. Sensores de pressão, temperatura e umidade estão dispostos na unidade e são acoplados ao computador. $\mathrm{O}$ acionamento dos equipamentos e o processamento dos dados são realizados de forma automatizada por meio do software LabviewTM 8.6, através de instrumentos virtuais (VI). Uma bomba peristáltica (Cole Parmer, 7780-60, Masterflex L/S) é utilizada para o transporte da solução ligante até um bico atomizador do tipo duplo fluido (Spraying Systems, SU12A). A Figura 1 apresenta o sistema experimental.

Figura 1 - Sistema experimental

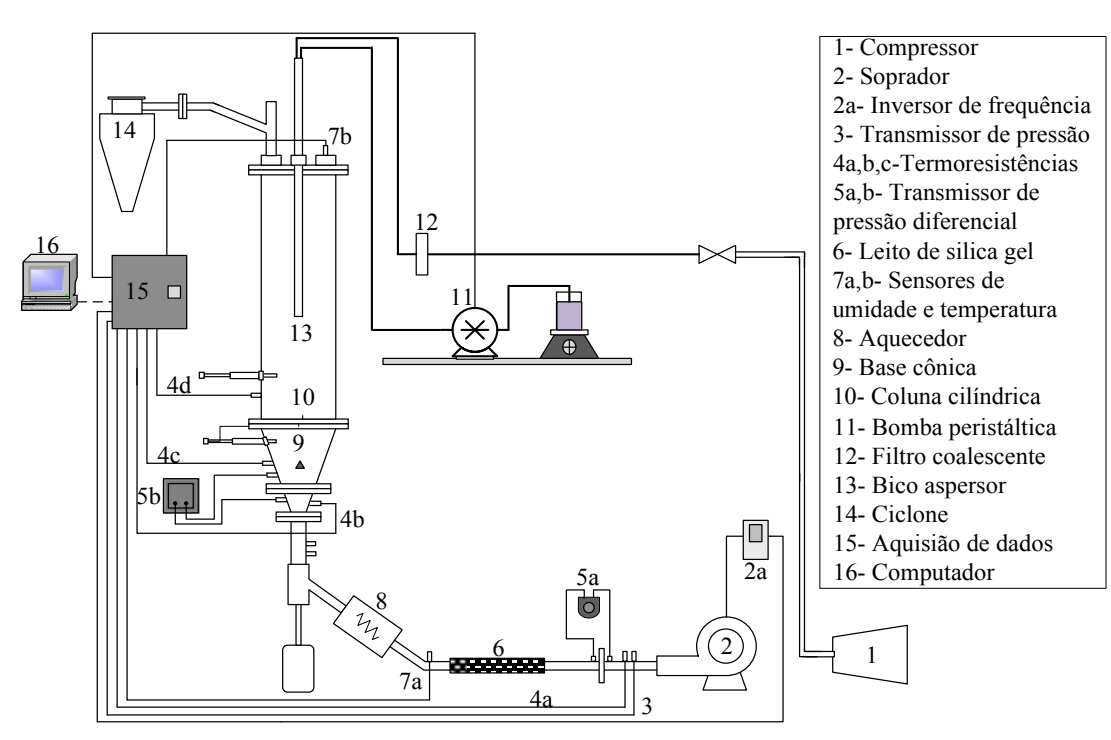




\subsection{Caracterização da Matéria-Prima e do Produto Aglomerado}

A caracterização físico-química da matéria-prima e do produto aglomerado consistiu na realização de análises de teor de umidade, diâmetro médio de partícula, tempo de instantaneização e fluidez. $\mathrm{O}$ teor de umidade foi determinado em estufa a $105^{\circ} \mathrm{C}$ até peso constante (AOAC, 1995). Foi considerado como desejável, um produto aglomerado com umidade final menor ou igual à umidade da matéria-prima. $\mathrm{O}$ diâmetro médio $\left(\mathrm{D}_{50}\right)$ das partículas da matéria-prima e do produto aglomerado, exceto nas condições do ponto central, foi determinado por difração a laser através do equipamento Mastersizer 3000 (Malvern Instruments).

Tempo de instantaneização: O tempo de instantaneização é o tempo necessário para a submersão de todas as partículas do pó, após serem colocadas sobre a superfície de um líquido. Essa análise foi realizada de acordo com Dacanal e Menegalli (2010) e utilizou-se 2g de amostra e $60 \mathrm{~mL}$ de água destilada. O teste de instantaneização foi acompanhado por meio de uma câmera digital (Sony Cyber) e as imagens foram processadas com o auxílio do software Windows Live Movie Maker. O teste foi finalizado quando ocorreu a submersão completa da camada de partículas. Foi considerado como desejável, tempo de instantaneização menor que o obtido para a matéria-prima.

Fluidez: A fluidez, que é a facilidade em que um determinado material particulado escoa, foi avaliada através do índice Carr $\left(I_{C a r r}\right)$ (Equação 1). O índice de Carr foi calculado empregando-se a densidade do leito $\left(\rho_{\mathrm{b}}\right)$ e a densidade do leito compactado $\left(\rho_{\mathrm{t}}\right)$. Na Tabela 1 é apresentada a relação entre o índice de Carr e a fluidez do material. Escoamento livre ou bom escoamento foram considerados como sendo desejáveis para o produto aglomerado.

$$
I_{\text {Carr }}(\%)=\frac{\rho_{t}-\rho_{b}}{\rho_{t}} \times 100
$$

Tabela 1 - Relação entre o índice de Carr $\left(I_{\text {Carr }}\right)$ e a fluidez (TURCHIULI et al.,2005)

\begin{tabular}{cc}
\hline$I_{\text {Carr }}(\%)$ & Nível de fluidez \\
\hline$I_{\text {Carr }}<15$ & Escoa livremente \\
$15-20$ & Bom escoamento \\
$20-35$ & Moderado \\
$35-45$ & Coesivo \\
$I_{\text {Carr }}>45$ & Muito coesivo \\
\hline
\end{tabular}

\subsection{Procedimento Experimental}

Para a realização do processo de aglomeração de proteína concentrada do arroz em leito fluidizado, utilizou-se como agente ligante uma solução de maltodextrina $20 \%$. A pressão de atomização utilizada foi de 15 psi e a vazão do ar de fluidização foi de $0,11 \mathrm{~kg} / \mathrm{m}^{3}$. O procedimento experimental consistiu, primeiramente, da alimentação do leito com $400 \mathrm{~g}$ de material. Em seguida, foram acionados o soprador de ar e a resistência elétrica. Após 5 minutos de aquecimento do sistema, acionou-se a bomba peristáltica, iniciando-se a 
alimentação da solução ligante. Para cada experimento padronizou-se como sendo o final do processo a adição completa de $100 \mathrm{~mL}$ de solução ligante.

Os ensaios foram realizados de forma aleatória de acordo com um planejamento fatorial completo $2^{2}$ com três repetições no ponto central. As variáveis independentes foram temperatura do ar $\left(60-80{ }^{\circ} \mathrm{C}\right)$ e vazão de solução ligante $(1,5-2,5 \mathrm{~mL} / \mathrm{min})$, codificadas como X1 e X2, respectivamente. As respostas do planejamento foram umidade final e rendimento do processo. A análise estatística foi realizada com auxilio do software Statistica ${ }^{\circledR} 8.0$, considerando limite de confiança de $95 \%(p \leq 0,05)$. O rendimento do processo $(\eta \%)$ foi obtido por meio da Equação 2, sendo definido como a razão entre a massa de produto remanescente no leito ao final dos ensaios $\left(m_{f}\right)$ e a massa inicial de produto adicionado no leito $\left(m_{i}\right)$. Desconsiderou-se a fração de material elutriado $\left(m_{\text {elut }}\right)$ e as perdas decorrentes da incrustação de produto na parede do leito $\left(m_{\text {inc }}\right)$, ou pela formação de torrões $\left(m_{\text {torrões }}\right)$.

$$
\eta(\%)=\frac{m_{f}}{m_{i}}=\frac{m_{i}-\left(m_{\text {elut }}-m_{\text {inc }}-m_{\text {torrões }}\right)}{m_{i}}
$$

\section{RESULTADOS E DISCUSSÃO}

A matéria-prima apresentou umidade de $4,65 \%$, diâmetro médio de $54,2 \mu \mathrm{m}$, nível de fluidez moderado representado pelo $I_{\text {Carr }}=30 \%$ e tempo de instantaneização de 140 segundos.

Os resultados de umidade final, rendimento do processo e diâmetro médio para as condições estudadas no planejamento experimental estão apresentados na Tabela 2.

Tabela 2 - Variáveis codificadas, reais e respostas do planejamento experimental e diâmetro médio de partícula

\begin{tabular}{cccccccc}
\hline \multirow{2}{*}{ Ensaios } & \multicolumn{2}{c}{$\begin{array}{c}\text { Variáveis } \\
\text { codificadas }\end{array}$} & \multicolumn{2}{c}{ Variáveis reais } & \multicolumn{2}{c}{ Respostas } \\
\cline { 2 - 8 } & $\mathrm{X}_{1}$ & $\mathrm{X}_{2}$ & $\begin{array}{c}\mathrm{T} \\
\left({ }^{\circ} \mathrm{C}\right)\end{array}$ & $\begin{array}{c}\mathrm{Q}_{\text {sol }} \\
(\mathrm{mL} / \mathrm{min})\end{array}$ & $\begin{array}{c}\mathrm{U} \\
(\% \mathrm{~b} . \mathrm{u})\end{array}$ & $\begin{array}{c}\eta \\
(\%)\end{array}$ & $\begin{array}{c}\mathrm{D}_{50} \\
(\mu \mathrm{m})\end{array}$ \\
\hline 1 & -1 & -1 & 60 & 1,5 & 7,40 & 63,69 & 97,38 \\
2 & 1 & -1 & 80 & 1,5 & 4,64 & 58,85 & 100,88 \\
3 & -1 & 1 & 60 & 2,5 & 11,40 & 72,31 & 90,59 \\
4 & 1 & 1 & 80 & 2,5 & 6,60 & 61,49 & 85,76 \\
$5(\mathrm{PC})$ & 0 & 0 & 70 & 2,0 & 7,35 & 65,27 & - \\
$6(\mathrm{PC})$ & 0 & 0 & 70 & 2,0 & 7,46 & 66,49 & - \\
$7(\mathrm{PC})$ & 0 & 0 & 70 & 2,0 & 7,82 & 67,61 & - \\
\hline
\end{tabular}

$\mathbf{X}_{1}$, T: Temperatura do ar; $\mathbf{X}_{2}, \mathbf{Q}_{\mathbf{s o l}}$ : vazão de solução ligante; $\mathbf{U}_{\mathrm{bu}}$ : umidade em base úmida; $\boldsymbol{\eta}$ : rendimento; $\mathbf{D}_{\mathbf{5 0}}$ :diâmetro médio; PC: ponto central.

Pela Tabela 2 é possível constatar que maiores diâmetros de partículas foram obtidos para menores vazões de solução atomizada. A menor vazão de solução ligante atomizada favoreceu o aumento do tamanho das partículas, uma vez que o regime de fluidização 
permaneceu estável até o final do processo, o que foi observado visualmente. Provavelmente, houve um equilíbrio entre o balanço da evaporação do ligante e a taxa de secagem, propiciando o crescimento dos grânulos. Para maiores vazão de solução ligante, observou-se uma tendência a defluidização do leito à medida que o processo evoluía, o que provavelmente dificultou a secagem e, consequentemente, prejudicou a consolidação e coalescência dos grânulos, impedindo o seu crescimento. A condição de maior temperatura e menor vazão de solução ligante (ensaio 2) foi a única condição na qual obteve-se umidade final menor ou igual a umidade da matéria-prima $\mathrm{A}$ variação na temperatura do ar não teve uma correlação clara com o diâmetro médio das partículas.

A Tabela 3 mostra a influência dos efeitos principais e de suas interações nas respostas estudadas. Verifica-se que ambas as variáveis operacionais tiveram efeitos significativos na umidade final e no rendimento do processo, para um limite de confiança de 95\%. Observa-se ainda que, o efeito da temperatura do ar apresentou uma influência negativa, o que significa que com o aumento da temperatura do ar a umidade final do produto e o rendimento do processo diminuíram.

Tabela 3 - Estimativa dos efeitos para as respostas do planejamento experimental

\begin{tabular}{lllll}
\hline \multicolumn{1}{c}{$\begin{array}{c}\text { Variáveis } \\
\text { operacionais }\end{array}$} & \multicolumn{2}{c}{$\mathbf{U}_{\text {b.u }}$ (umidade) } & \multicolumn{2}{c}{$\boldsymbol{\eta}(\%)$ (rendimento) } \\
\hline & Efeito & $P$ & Efeito & $P$ \\
\hline Média & 7,52 & 0,0001 & 65,10 & 0,00004 \\
$\mathrm{~T}\left({ }^{\circ} \mathrm{C}\right)\left(\mathrm{X}_{1}\right) *$ & $-3,78$ & $0,004^{*}$ & $-7,83$ & $0,021^{*}$ \\
$\mathrm{Q}_{\text {sol }}(\mathrm{mL} / \mathrm{min})\left(\mathrm{X}_{2}\right)^{*}$ & 2,98 & $0,006^{*}$ & 5,63 & $0,040^{*}$ \\
$\mathrm{X}_{1} * \mathrm{X}_{2}$ & $-1,02$ & 0,053 & $-2,99$ & 0,125 \\
\cline { 2 - 5 } *efeitonificativos para um limite de confiança de $95 \%(p \leq 0,05)$.
\end{tabular}

Ainda constatou-se que a vazão de solução ligante apresentou um efeito positivo sobre as respostas umidade final e rendimento do processo. Isso demonstra que o aumento da vazão de ligante resultou em maior umidade final e rendimento do processo. Esses resultados corroboram com os resultados obtidos por Dacanal e Menegalli (2010) que estudaram a aglomeração da proteína isolada de soja. A interação entre as variáveis independentes não teve influência significativa nas respostas umidade final e rendimento do processo.

Na Tabela 4 constam os resultados de nível de fluidez e tempo de instantaneização para as condições estudadas. Verificou-se que aumento no tamanho das partículas ocasionado pelo processo de aglomeração melhorou o nível de fluidez e diminuiu o tempo de instantaneização do material. Para todas as condições estudadas o produto aglomerado apresentou bom escoamento, exceto na condição com menor temperatura do ar $\left(60^{\circ} \mathrm{C}\right)$ e maior vazão de solução ligante $(2,5 \mathrm{~mL} / \mathrm{min})$, em que o escoamento foi moderado. Nessa condição, o produto apresentou elevada umidade final $(11,40 \%$ b.u $)$, o que provavelmente afetou sua escoabilidade. $\mathrm{O}$ produto aglomerado apresentou menor tempo de instantaneização quando comparado com a matéria-prima, para todas as condições estudadas. Esse resultado é devido ao aumento do tamanho das partículas, que permitiu a penetração de líquido no seu interior de forma mais rápida (HOGEKAMP e SCHUBERT, 2003). Também se observa que maiores temperaturas resultaram em menores tempos de instantaneização, o que pode estar 


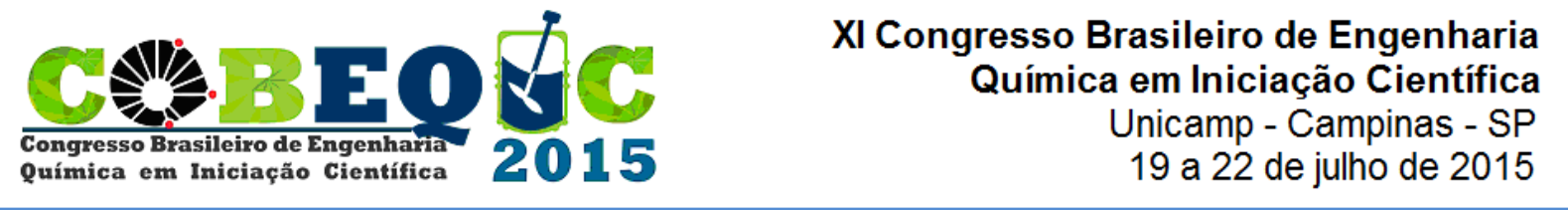

relacionado com a umidade do produto, que foi menor para maiores temperaturas, facilitando a penetração da água no interior dos grânulos.

Tabela 4 - Nível de fluidez e tempo de instantaneização para o produto aglomerado

\begin{tabular}{cccccl}
\hline Testes & $\mathrm{T}\left({ }^{\circ} \mathrm{C}\right)$ & $\mathrm{Q}_{\text {sol }}(\mathrm{mL} / \mathrm{min})$ & $\begin{array}{c}\text { Tempo de } \\
\text { instantaneização }(\mathrm{s})\end{array}$ & $I_{\text {Carr }}$ & Nível de Fluidez \\
\hline 1 & 60 & 1,5 & 90 & 15 & Bom escoamento \\
2 & 80 & 1,5 & 36 & 19 & Bom escoamento \\
3 & 60 & 2,5 & 85 & 23 & Moderado \\
4 & 80 & 2,5 & 22 & 20 & Bom escoamento \\
$5(\mathrm{PC})$ & 70 & 2,0 & 43 & 20 & Bom escoamento \\
$6(\mathrm{PC})$ & 70 & 2,0 & 47 & 20 & Bom escoamento \\
$7(\mathrm{PC})$ & 70 & 2,0 & 39 & 20 & Bom escoamento \\
\hline
\end{tabular}

\section{CONCLUSÃO}

O processo de aglomeração resultou no aumento do diâmetro médio do material, o que melhorou seu nível de fluidez e proporcionou melhores propriedades de instantaneização, viabilizando sua utilização em diversas aplicações. A condição estudada que proporcionou umidade final, fluidez e tempo de instantaneização desejáveis foi para temperatura do ar de 80 ${ }^{\circ} \mathrm{C}$ e vazão de solução ligante de $1,5 \mathrm{~mL} / \mathrm{min}$, apesar de nessa condição o rendimento do processo ter sido menor $(58,85 \%)$. Nessa condição o produto aglomerado apresentou umidade final de $4,64 \%$, bom escoamento e tempo de instantaneização de 36 segundos.

\section{REFERÊNCIAS BIBLIOGRÁFICAS}

AOAC. Official methods of analysis of the Association of official analytical chemists.16 ed. Washington, 1995.

DACANAL, G. C.; MENEGALLI, F. C. Selection of operational parameters for the production of instant soy protein isolate by pulsed fluid bed agglomeration. Powder Technol., v. 203, p. 565-573, 2010.

HOGEKAMP, S.; SCHUBERT, H. Rehydration of food powders. Food Sci.Technol. Int., v. 9, p. 223-235, 2003.

IVESON, S. M.; LITSTER, J. D.; HAPGOOD, K.; ENNIS, B. J. Nucleation, growth and breakage phenomena in agitated wet granulation processes: a review. Powder Technol., v. 117, p.3-39, 2001.

JULIANO, B. O. Rice in human nutrition. Rome: FAO, 1993. 168 p.

KUNII, D.; LEVENSPIEL, O. Fluidization Engineering. New York: John Wiley, 1991.

TURCHIUli, C.; ELOUALIA, Z.; MANSOURI, N. E.; DUMOULIN, E. Fluidised bed agglomeration: Agglomerates shape and end-use properties. Powder Technol., p. 168$175,2005$. 